Research Article

\title{
Partially Smoothing and Gradient-Based Algorithm for Optimizing the VMI System with Competitive Retailers under Random Demands
}

\author{
Hua Deng, Yinxue Li, Zhaoman Wan $(D$, and Zhong Wan (iD \\ School of Mathematics and Statistics, Central South University, Changsha, China \\ Correspondence should be addressed to Zhong Wan; wanmath@163.com
}

Received 12 September 2019; Revised 20 December 2019; Accepted 26 December 2019; Published 16 March 2020

Academic Editor: Ching-Ter Chang

Copyright (c) 2020 Hua Deng et al. This is an open access article distributed under the Creative Commons Attribution License, which permits unrestricted use, distribution, and reproduction in any medium, provided the original work is properly cited.

\begin{abstract}
Vendor managed inventory (VMI) is an improved sustainable inventory management system, but it is difficult to establish and solve an integrated Stackelberg game model under the complicated practical environment. In this paper, a bilevel programming model is proposed to formulate the VMI system by taking into account the uncertainty of demand, the competition among retailers, the cooperative advertising, the shortage and holding costs, and the practical constraints. For the established stochastic model being associated with continuously random demands, a deterministic mathematical program with complementarity constraints (MPCC) is first derived by expectation method and the first-order optimality conditions of the lower-level problem. Then, with a partially smoothing technique, the MPCC is solved by transforming it into a series of standard smooth optimization subproblems. Finally, owing to complexity caused by evaluating the integrals with unknown decision variables in the objective function, an efficient algorithm is developed to solve the problem based on the gradient information of model. Sensitivity analysis has been employed to reveal a number of managerial implications from the constructed model and algorithm. (1) The participation rate depends on advertising expenditures from both the manufacturer and the retailer. There exists an optimal threshold of participation rate for the manufacturer, which can be provided by the intersection point of the manufacturer and retailer's costprofit curves. (2) The manufacturer's advertising policy is less sensitive to uncertainty of demand than the change of the retailer's advertising policy. (3) The manufacturer in the VMI system should concern about the differences caused by symmetric or asymmetric retailers.
\end{abstract}

\section{Background}

Vendor managed inventory (VMI) is an improved sustainable inventory management system with cooperative strategy between vendors (manufacturers) and buyers (retailers) [1]. When the information flows from the retails to the manufacturers, the VMI system can reduce fluctuation amplification of the customers' demand. More precisely, it mitigates the bullwhip effect. Actually, owing to benefits of the VMI mode, it has been a well-known industry practice for supply chain collaboration such as in Walmart, Campbell, and Intel $[2,3]$.

Different from an ordinary supply chain, the vendor in the VMI system would like to take greater responsibility for operational costs of the system than the buyers such that the total profit of system can be maximized. Therefore, instead of centralized decision-making in an ordinary supply chain, how to make an optimal operational strategy for the VMI system is basically in a framework of the Stackelberg game, in which the vendor is the leader and the buyers are the followers $[4,5]$. However, in the research of VMI system based on the game theory, the following issues need to be further addressed:

(i) It is clear that the demand of customers is the basis of making-decision in the VMI system. Since the demand is a coherent result of interrelation and interaction of many factors, such as pricing and advertising policies, and consumer behavior, how to establish an integrated model to incorporate these factors is worthy of deeper investigation. 
(ii) In the case that the established model of VMI system is complicated as it is more in line with the practical operational process of this system, the question is how to develop an algorithm to efficiently find its solution?

(iii) Is the proposed complicated model more valuable in practice than the existing ones or not?

In the next section, we will summarize the results available in the literature related to these questions. In particular, from the viewpoint of more applicability of models, we concern what are the deficiencies of these results.

\section{Literature Review}

2.1. Bilevel Programming Models of VMI. Generally, vendors and buyers are the independent entities in a typical VMI system, who own their respective costs and profits [2]. Different from an ordinary supply chain, the vendor (also called a manufacturer) in such a system is primarily responsible for determining the ordering policy for its buyers (also called the retailers), including reorder items, related replenishment quantities, delivery times, and safety inventory [6]. Each retailer provides its real-time inventory level to the vendor via physical or electronic messaging. In the case that there are multiple retailers for the same vendor, transaction behavior among these retailers is also critical to achieve efficient supply chain $[7,8]$. Owing to the inherent features of the VMI system, as done by many researchers (see the articles listed in Table 1), it is natural to use the Stackelberg game to describe the relationship between the vendor and retailers, where the vendor is the leader and the retailers are the followers.

Specifically, with assumption of fixed demands, Alaei et al. [9] discussed how the vendor (manufacture) coordinates the channel, in which two identical retailers compete on local advertising investment. Wang et al. [10] also studied two possible models of the Stackelberg game with the cooperative advertising issues of a monopolistic manufacturer with competing duopolistic retailers in the VMI system, where the selling prices of the retailers are assumed to be exogenously determined. For a VMI system composed of one vendor and multiple retailers, Almehdawe and Mantin [11] modeled the VMI framework by two scenarios of the Stackelberg game: either the manufacturer is the leader or one of the retailers acts as the dominant player. However, the demand in [11] is not random and only depends on the retailing price. SeyedEsfahani et al. [12] also described the relationship between the manufacturer and the retailer by the similar Stackelberg-manufacturer or Stackelberg-retailer games. Although the demand depends on both of vertical cooperative advertising strategy and pricing decisions in [12], no competition between the retailers was studied, and the optimal decisions were derived without any practical constraints.

2.2. VMI System with Cooperative Advertising. Since advertising investment is often an efficient way to provide customers with the brand knowledge of products and services in time, cooperative (coop) advertising strategy between the vendor and the retailers is often adopted in a practical VMI system. It was shown [13] that the offer from the vendor to bear a certain percentage of his/her retailers' advertising expenditures can encourage the retailers into more promotional initiatives.

To the best of our knowledge, Berger [14] was the first to discuss coop advertising in a vendor-retailer channel. Based on his work, many results were obtained under different coop advertising settings (see, e.g., [15-17]). However, Herrington and Dempsey [18] argued that the vendor's global advertising could create a brand image and makes for publicity and reputation of the product but does not necessarily lead to real consumer demand, while the retailer's local advertising treats more of promotions and prices. Somers et al. [19] thought that it might occur that the retailer's advertising level is not sufficient from the vendor's point of view.

In practice, the vendor would not like to undertake all the costs of local advertising which may bring additional revenue to the retailers. Taking into consideration the vendor's global advertising besides the retailer's local advertising, Giri and Sharma [20] developed a two-level supply chain model under coop advertising setting. Xie and Wei [21] assumed that the customer demand depends on retail prices as well as advertising efforts of channel members. Gerhard and Udo [22] constructed a manufacturer-retailer supply chain model by optimizing the coop advertising and pricing decisions. A bargaining model was established by considering the four scenarios of symmetric and noncooperative relationship, asymmetric relationship with manufacturer-leadership, and asymmetric relationship with retailer-leadership and cooperation. Karray and Zaccour [23] also suggested that the demand depends not only on his/her own advertising but also on the advertising of competitors. De Giovanni [24] assessed the effects of cooperative advertising programs in bilateral monopolies. For more details, one can see $[25,26]$ and the references therein. However, in these articles, effect of interaction between advertising and pricing policies has not been modeled in the demand functions. To improve applicability of models, it is desirable to incorporate the interaction of pricing strategy and advertising investment into the demand model.

2.3. VMI System with Random Demand. Owing to asymmetry information and market uncertainty, the customers' demand is often time-varying, especially being faced with variants of selling policies [27, 28].

Kiesmüller and Broekmeulen [3] studied a supply chain management problem of multiproduct serial two-echelon inventory system with stochastic demand by three different VMI strategies to reduce the order picking cost at the upstream location and the transportation costs resulting in reduced total supply chain costs. A detailed numerical study was used to show the differences between the VMI strategies and the retailer managed inventory strategy. Lee and Ren [29] proposed a periodic-review inventory model with 
TABLe 1: Relevant results on VMI by the Stackelberg game.

\begin{tabular}{|c|c|c|c|c|c|}
\hline Authors & Stackelberg game & $\begin{array}{l}\text { Interaction of } \\
\text { retailers }\end{array}$ & $\begin{array}{l}\text { Random } \\
\text { demand }\end{array}$ & $\begin{array}{c}\text { Constrained or } \\
\text { not }\end{array}$ & Solution methods \\
\hline Berger (1972) & 1 vendor and 1 retailer & $\checkmark$ & $x$ & $\checkmark$ & $\begin{array}{l}\text { Lagrange function } \\
\text { method }\end{array}$ \\
\hline Karray et al. (2007) & 2 vendors and 2 retailers & $\checkmark$ & $\times$ & $\checkmark$ & Noncooperative game \\
\hline Almehdawe et al. (2010) & 1 vendor and $n$ retailers & $x$ & $\times$ & $\checkmark$ & KKT conditions \\
\hline Kiesmüller et al. (2011) & $n$ vendors and $n$ retailers & $x$ & $\checkmark$ & $x$ & Expectation method \\
\hline Bylka (2011) & 1 vendor and 1 retailer & $x$ & $x$ & $\checkmark$ & Noncooperative game \\
\hline Tsao et al. (2014) & 1 vendor and $n$ retailers & $x$ & $x$ & $\checkmark$ & Piecewise linearization \\
\hline Giri et al. (2014) & 1 vendor and 2 retailers & $\checkmark$ & $x$ & $\times$ & Second-order conditions \\
\hline Mateen et al. (2014) & 1 vendor and 4 retailers & $x$ & $\checkmark$ & $\checkmark$ & Simulation method \\
\hline Haji et al. (2018) & $\begin{array}{l}1 \text { supplier, } 1 \text { vendor, and } 1 \\
\text { retailer }\end{array}$ & $\times$ & $\checkmark$ & $\times$ & Enumerative algorithm \\
\hline Wei et al. (2019) & 1 vendor and 1 retailer & $x$ & $\checkmark$ & $\times$ & Backward induction \\
\hline Huang et al. (2019) & 1 vendor and 1 retailer & $x$ & $\checkmark$ & $x$ & First-order conditions \\
\hline Our study & 1 vendor and $n$ retailers & $\checkmark$ & $\checkmark$ & $\checkmark$ & $\begin{array}{l}\text { Gradient-based and } \\
\text { smoothing }\end{array}$ \\
\hline
\end{tabular}

stochastic exchange rate to examine the benefits of VMI in a global environment. Compared with the case of no uncertain exchange rate, the total cost of supply chain always decreases under VMI and its reduction is larger when there exists uncertainty of exchange rate. By assuming that the vendor replenishes all the retailers at the same time, Mateen et al. [1] studied an integer programming model of a VMI system with a single vendor and multiple retailers under stochastic demand. Then, an approximate expression for minimizing the expected total cost of the VMI system was given such that it can be solved by a software package. In a three-echelon supply chain system with multiple lossaverse retailers, risk-neutral manufacturers, and riskneutral distributer, Ming et al. [30] constructed a decentralized decision model under stochastic demand, but the optimal solution was given without considering any practical constraints. Under random demand, Huynh and Pan [31] presented a model of operational strategies for a VMI system of one retailer and one manufacturer. Since no practical constraint was considered and the demand does not depend on the retailing price, an optimal solution of the model was analytically derived in [31]. Govindan [32] studied a model of minimizing the total cost of VMI system with one vendor and multiple retailers under time-varying stochastic demand. Huang et al. [33] considered that the stochastic demand depends on product quality level and marketing effort level. Haji et al. [34] assumed that the retailer's demand satisfies the Poisson distribution. Zhang et al. [35, 36] proposed two stochastic programming models to formulate the management problem of global supply chains in the case that product demands are continuous random variables. Wei et al. [37] studied two different inventory management models with considering stochastic learning effect. Owing to the complexity caused by evaluating the integrals with the unknown decision variables in the objective function, it was pointed out in [35] that the existing optimization algorithms, or the software packages such as MATLAB, CPLEX, and LINGO, cannot be directly used to solve the models. Therefore, for the stochastic models with continuous random demands, it is valuable to develop an efficient algorithm to solve them based on the gradient information of the objective function and constraints.

However, all of the above mentioned VMI (or supply chain) models are not based on the Stackelberg game theory. Moreover, in these models, effects of (coop) advertising policies and interaction of pricing and advertising policies have not been considered in the demand models.

2.4. Intentions of This Research. Motivated by improving applicability of model and overcoming the deficiency of the existing results on the VMI problems, we attempt to propose a new Stackelberg game model to formulate the VMI management problem under assumption of continuous random demands (see the comparison made in Table 1). In our model, all of the delivered quantities, advertising investments, and prices of products are treated as the endogenous variables of the model, and the demand is priceand-advertisement-dependent and is supposed to be a continuous random variable such that it is more in line with the practical marketing environment. Owing to uncertainty in our model, it is necessary to incorporate shortage loss and holding cost into this model.

More importantly, different from the models available in the literature [5], possible competition among the multiple retailers is considered in the new model. In other words, the product demand of one retailer in this VMI system depends not only on its own pricing and advertising policies but also on those of the other retailers. Moreover, possible interaction between pricing and advertising policies will also be modeled in the demand function of this research.

Apart from establishment of a new model, we also need to answer the following questions:

(i) For the complicated bilevel programming model, how can we develop an efficient algorithm to find its equilibrium solution? Particularly, without assumption of simplification as in [11,38-40], we need to first derive a deterministic equivalent formulation by expectation method for the stochastic nonlinear 
bilevel programming model $[41,42]$. Then, similar to the approach in [5], it is necessary to convert the bilevel programming problem into the mathematical program with complementarity constraints (MPCC) such that a series of standard smooth optimization subproblems can be solved $[43,44]$. Since the expected profit in the new model is involved in computing integrals being associated with the unknown decision variables, an efficient algorithm, rather than heuristic algorithms, is more desirable to find an equilibrium of this complicated nonlinear model.

(ii) What are the valuable managerial implications revealed from the new model? Specifically, (1) what are the impacts of the market parameters on the profit of retailers and the demand? (2) What are the impacts of the uncertainty in the demand function on the profit of retailers? (3) As the manufacturer's profit reaches the maximum, what is the value of participation rate (the advertising expenditure ratio of retailer to that born by the manufacturer)? (4) What are the impacts of the advertising coefficient of sensitivity on the participation rate? (5) What are the impacts of the manufacturing cost and shortage cost on the manufacturer's profit?

The rest of this paper is organized as follows. The next section is devoted to formulation of the bilevel programming model for the VMI system. Then, the bilevel programming model is reformulated as a series of standard smooth optimization problems in Section 4. In Section 5, gradientinformation based algorithm for solving the model is developed. Sensitivity analysis of the model is conducted in Section 6. Some conclusions are drawn in the last section.

\section{Bilevel Programming Model for VMI Problems}

In this section, we will model the VMI problem as a bilevel mathematical programming problem.

We first make the following settings to specify the handled problem in this paper:

(i) The VMI system is composed of a manufacturer (vendor) and multiple retailers. All of them are riskneutral to uncertainty of product demands.

(ii) The manufacturer produces only one type of finished products and distributes them to its retailers at the same wholesale price.

(iii) Each retailer can sell the finished products to the consumers at different retail prices. Among the retailers, there exists competition in terms of pricing and advertising polices. In other words, for each retailer, the demand depends not only on his/her own advertising expenditure and retail price but also on those of the other retailers.

(iv) The market demand may depend on the retail prices and the advertising expenditures from both the manufacturer and all the retailers and is of random nature (see, e.g., $[9,12,13])$. Mathematically, if we denote by $p_{-i}$ and $a_{-i}$ the retail prices and the advertising expenditures of all the retailers except for retailer $i$, respectively, then the demand of retailer $i$ reads

$$
D_{i}\left(p_{i}, a_{i} ; A, p_{-i}, a_{-i}, \xi_{i}\right)=d_{i}\left(p_{i}, a_{i} ; A, p_{-i}, a_{-i}\right)+\xi_{i},
$$

where $d_{i}: R_{+} \longrightarrow R$ is a function with respect to the retail prices $p_{i}$ and $p_{-i}$, the advertising expenditures of all the retailers $a_{i}$ and $a_{-i}$, and the advertising expenditures of the manufacturer $A$, and $\xi_{i}$ is a random variable.

3.1. Notations. For readability, we list the notations used in this paper as follows:

\section{Indices}

$i$ : Index of retailers, $i=1,2, \ldots, m$

$m$ : Number of retailers.

Parameters

$c_{m}$ : Unit manufacturing cost of the manufacturer (\$/unit)

$c_{p}$ : Unit wholesale price of finished products (\$/unit)

$H_{i}^{R}$ : Unit holding cost paid by the manufacturer at the location of retailer $i$ ( $\$ /$ unit/time)

$I_{i}$ : Unit inventory cost paid by retailer $i$ ( $\$ /$ unit/time)

$L_{i}^{R}$ : Unit shortage cost paid by the manufacturer to retailer $i$ (\$/unit/time)

$P$ : Production capacity of the manufacturer

$S^{M}$ : Fixed operational cost of the manufacturer

$S_{i}^{R}$ : Fixed operational cost of retailer $i$

$T_{i}$ : Unit transportation cost of the finished products shipped from the manufacturer to retailer $i$ (\$/unit) $t_{i}$ : Advertising expenditure ratio of retailer $i$ to that born by the manufacturer ( $\$$ unit)

TDC: Total direct cost for the manufacturer (\$/time) TIDC: Total indirect cost of the manufacturer (\$/time) $\pi_{i}^{R}$ : Profit of retailer $i$ ( $\$ /$ time)

$\pi^{M}$ : Profit of the manufacturer (\$/time)

$p_{-i}$ : Price profile of all the other retailers except for retailer $i$

$a_{-i}$ : Advertisement profile of all the other retailers except for retailer $i$

$\alpha$ : The basic minimum demand

$\beta_{i}$ : The retail price sensitivity coefficient of retailer $i$

$\rho_{i j}$ : The sensitivity coefficient of competitor $j$ to the retail price for retailer $i$

$\tau_{i j}$ : The sensitivity coefficient of competitor $j$ to the advertising expenditure for retailer $i$

$k$ : The basic market size

$k_{i}$ : The advertising sensitivity coefficient of retailer $i$

$k_{m}$ : The advertising sensitivity coefficient of the manufacturer.

Decision variables of the retailers

$p_{i}$ : Unit retail price in the market of retailer $i$ (\$/unit) $p$ : A vector of retail prices, $p=\left(p_{1}, p_{2}, \ldots, p_{m}\right)$ 
$a_{i}$ : Advertising expenditure of retailer $i$ ( $\$$ time) $a$ : Vector of advertising expenditures of retailers, $a=$ $\left(a_{1}, a_{2}, \ldots, a_{m}\right)$.

\section{Decision variables of the manufacturer}

$q_{i}$ : Distributed quantity from the manufacturer to retailer $i$

$q$ : Vector of distributed quantities, $q=\left(q_{1}, q_{2}, \ldots, q_{m}\right)$

$A$ : Advertising expenditure of the manufacturer (\$/time).

3.2. Demand Function. In order to specify the profit functions, we assume that the demand in (1) is defined by

$$
\left\{\begin{array}{l}
d_{i}\left(p_{i}, a_{i} ; A, p_{-i}, a_{-i}\right)=\left(\alpha-\beta_{i} p_{i}+\sum_{j \neq i} \rho_{i j} p_{j}\right) \\
\left(k+k_{m} \sqrt{A}+k_{i} \sqrt{a_{i}}-\sum_{j \neq i} \tau_{i j} \sqrt{a_{j}}\right), \\
\xi_{i} \backsim f_{i}\left(\xi_{i}\right),
\end{array}\right.
$$

where $\alpha>0, \beta_{i}>0, \rho_{i j}>0, k>0, k_{m}>0, k_{i}>0$, and $\tau_{i j}>0$ are given constants, and $f_{i}$ is the density function of the continuous random variable $\xi_{i}$ with a support set $[0,+\infty)$. In practice, $\alpha$ and $k$ determine the basic minimum demand and the market size, respectively. $\beta_{i}$ and $\rho_{i j}$ stand for the own price sensitivity and that of the competitor $j$, respectively. Clearly, for each retailer, the decrease in its own price and the increasing price of its competitor $j$ often result in the increasing market demand of this retailer. $k_{m}$ is the advertising expenditure sensitivity coefficient of the manufacturer. $k_{i}$ and $\tau_{i j}$ stand for the sensitivity to the own advertising expenditures $\left(k_{i}\right)$ and that to the competitor $j$, respectively. It is easy to see that the consumer demand increases as the own advertising expenditure goes up and that of the competitor $j$ goes down. $p_{i}$ and $p_{j}$ are the retail prices of retailer $i$ and its competitor $j$, respectively. $a_{i}$ and $a_{j}$ are the advertising expenditures of retailer $i$ and its competitor $j$, respectively. $A$ is the advertising expenditure of the manufacturer.

As for randomness of demand, we suppose that $\xi_{i}$ is subject to normal distribution. In particular, if $\xi_{i} \sim N\left(\mu_{i}, \sigma_{i}^{2}\right), i=1,2, \ldots, m$, the cumulative distribution function of $\xi_{i}$, denoted by $F_{i}$, is specified by

$$
\begin{aligned}
F_{i}(x) & =F_{i}\left(x ; \mu_{i}, \sigma_{i}\right)=\int_{-\infty}^{x} f_{i}\left(\xi_{i}\right) \mathrm{d} \xi_{i} \\
& =\int_{-\infty}^{x} \frac{1}{\sqrt{2 \pi} \sigma_{i}} e^{-\left(\xi_{i}-\mu_{i}\right)^{2} / 2 \sigma_{i}^{2}} \mathrm{~d} \xi_{i},
\end{aligned}
$$

which will be used to maximize the profits. In general, $\mu_{i}=0$ (see $[36,45]$ ).

It should be pointed out that there are different available approaches to describing the demands in the literature. Random multiplicity and additive demands are the two main formations, being used to address particular product markets and consumer demands (see $[35,36])$. In this paper, we mainly focus on the random additive demand associated with the retail prices and the advertising expenditures such that a number of managerial implications are drawn from the constructed model and the developed algorithm.

3.3. Lower-Level Optimization Model for Retailers. Retailer $i$ faces the problem of determining the unit retail price $p_{i}$ and the advertising expenditure $a_{i}$ to maximize his/ her profit. The profit of retailer $i$ is given by

$$
\begin{aligned}
\pi_{i}^{R}\left(p_{i}, a_{i} ; q_{i}, A, p_{-i}, a_{-i}, \xi_{i}\right)= & p_{i} \min \left\{q_{i}, D_{i}\right\}-c_{p} q_{i} \\
& -I_{i} \min \left\{q_{i}, D_{i}\right\}-\left(1-t_{i}\right) a_{i}-S_{i}^{R} .
\end{aligned}
$$

The first term in equation (4) is the total revenue of retailer $i$. The remaining terms in equation (4) are the products' procurement cost, the inventory cost, the advertising expenditure, and the fixed operational cost, respectively. It is noted that the unit inventory cost for retailer $i$, as the VMI partnership, is only proportional to the quantity of products that have been sold by retailer $i$. In addition, in the coop advertising framework, the manufacturer would share a fraction of advertising expenditure of retailer $i$.

As the decision variables of retailer $i$, the unit retail price and the advertising expenditure should satisfy the following constraints:

$$
p_{i} \geq c_{p}+I_{i}, \quad a_{i} \geq 0 .
$$

Consequently, the lower-level optimization model for retailer $i, i=1,2, \ldots, m$, is given by

$$
\begin{array}{ll}
\max & \pi_{i}^{R}\left(p_{i}, a_{i} ; q_{i}, A, p_{-i}, a_{-i}, \xi_{i}\right)=\left(p_{i}-I_{i}\right) \min \left\{q_{i}, D_{i}\right\} \\
& -c_{p} q_{i}-\left(1-t_{i}\right) a_{i}-S_{i}^{R} \\
\text { s.t. } & p_{i} \geq c_{p}+I_{i}, \quad a_{i} \geq 0 .
\end{array}
$$

\subsection{Upper-Level Optimization Model for Manufacturer.}

The manufacturer faces the problem of determining optimal distributed quantities $q_{i}$ and an advertising expenditure $A$ to maximize his/her profit, a difference between the total revenue and the total cost.

The total revenue is

$$
\sum_{i=1}^{m} c_{p} q_{i}
$$

The total cost is divided into two parts: direct and indirect costs. The direct cost (TDC) includes the production cost, the transportation cost from the manufacturer to retailers, his/her own advertising expenditure, the burdened advertising expenditures for his/her retailers, and the fixed operational cost. Its mathematical expression is

$$
\sum_{i=1}^{m} q_{i}\left(c_{m}+T_{i}\right)+A+\sum_{i=1}^{m} t_{i} a_{i}+S^{M} .
$$

Since the inventory level is managed by the manufacturer, the manufacturer must be responsible for the retailers' holding costs and shortage costs caused by the variation in 
the replenishment cycle, which is a punishment for the manufacturer. Thus, the total indirect cost (TIDC) is the holding costs or shortage costs:

$$
\text { TIDC }=\sum_{i=1}^{m}\left(H_{i}^{R}\left(q_{i}-D_{i}\right)^{+}+L_{i}^{R}\left(D_{i}-q_{i}\right)^{+}\right),
$$

where $\left(D_{i}-Q_{i}\right)^{+}=\max \left\{D_{i}-Q_{i}, 0\right\}$. Consequently, we get the profit of the manufacturer as follows:

$$
\begin{aligned}
\pi^{M}(q, A ; p, a, \xi)= & \sum_{i=1}^{m} c_{p} q_{i}-\mathrm{TDC}-\mathrm{TIDC} \\
= & \sum_{i=1}^{m}\left(c_{p}-T_{i}-c_{m}\right) q_{i}-A-\sum_{i=1}^{m} t_{i} a_{i}-S^{M} \\
& -\sum_{i=1}^{m}\left(H_{i}^{R}\left(q_{i}-D_{i}\right)^{+}+L_{i}^{R}\left(D_{i}-q_{i}\right)^{+}\right) .
\end{aligned}
$$

Limited by production capacity and advertising expenditure, the manufacturer's decision variables should satisfy the following constraints:

$$
\sum_{i=1}^{m} q_{i} \leq P, \quad A \geq 0 .
$$

With the above analysis, we obtain the following upperlevel optimization model for the manufacturer:

$$
\begin{aligned}
\max & \pi^{M}(q, A ; p, a, \xi)=\sum_{i=1}^{m}\left(c_{p}-T_{i}-c_{m}\right) q_{i}-A-\sum_{i=1}^{m} t_{i} a_{i} \\
& -S^{M}-\sum_{i=1}^{m}\left(H_{i}^{R}\left(q_{i}-D_{i}\right)^{+}+L_{i}^{R}\left(D_{i}-q_{i}\right)^{+}\right) \\
\text {s.t. } & \sum_{i=1}^{m} q_{i} \leq P, \quad A \geq 0 .
\end{aligned}
$$

3.5. Bilevel Programming Model for VMI Problems. In light of Models (6) and (12), it is easy to establish a stochastic bilevel programming model for the handled VMI problem as follows:

$$
\begin{aligned}
\max & \pi^{M}(q, A ; p, a, \xi)=\sum_{i=1}^{m}\left(c_{p}-T_{i}-c_{m}\right) q_{i}-A-\sum_{i=1}^{m} t_{i} a_{i} \\
& -S^{M}-\sum_{i=1}^{m}\left(H_{i}^{R}\left(q_{i}-D_{i}\right)^{+}+L_{i}^{R}\left(D_{i}-q_{i}\right)^{+}\right)
\end{aligned}
$$$$
\text { s.t. } \quad \sum_{i=1}^{m} q_{i} \leq P, \quad A \geq 0 \text {. }
$$

$\left(p_{i}, a_{i}\right)$ is the solution of the following optimization problem:

$$
\begin{array}{lc}
\max & \pi_{i}^{R}\left(p_{i}, a_{i} ; q_{i}, A, p_{-i}, a_{-i}, \xi_{i}\right)=\left(p_{i}-I_{i}\right) \\
& \min \left\{q_{i}, D_{i}\right\}-c_{p} q_{i}-\left(1-t_{i}\right) a_{i}-S_{i}^{R} \\
\text { s.t. } & p_{i} \geq c_{p}+I_{i}, a_{i} \geq 0, \quad i=1,2, \ldots, m .
\end{array}
$$

Owing to existence of the random demand in (13), we first transform (13) into a deterministic equivalent formulation by expectation method. For simplification, denote

$$
z_{i}=q_{i}-d_{i}
$$

where $d_{i}$ is defined in (1). Then, the expected profit of the manufacturer reads

$$
\begin{aligned}
E^{M}= & E\left(\pi^{M}\right)=\sum_{i=1}^{m}\left(c_{p}-T_{i}-c_{m}\right) q_{i}-A-\sum_{i=1}^{m} t_{i} a_{i}-S^{M} \\
& -\sum_{i=1}^{m}\left(H_{i}^{R} \int_{0}^{z_{i}}\left(q_{i}-D_{i}\right) f\left(\xi_{i}\right) \mathrm{d} \xi_{i}+L_{i}^{R} \int_{z_{i}}^{+\infty}\left(D_{i}-q_{i}\right) f\left(\xi_{i}\right) \mathrm{d} \xi_{i}\right),
\end{aligned}
$$

and the expected profit of retailer $i$ is rewritten as

$$
\begin{aligned}
E_{i}^{R}=E\left(\pi_{i}^{R}\right)= & \left(p_{i}-I_{i}\right)\left(\int_{0}^{z_{i}} D_{i} f\left(\xi_{i}\right) \mathrm{d} \xi_{i}+\int_{z_{i}}^{+\infty} q_{i} f\left(\xi_{i}\right) \mathrm{d} \xi_{i}\right) \\
& -c_{p} q_{i}-\left(1-t_{i}\right) a_{i}-S_{i}^{R} .
\end{aligned}
$$

Thus, the deterministic equivalent formulation of Model (13) is given by

$$
\begin{array}{ll}
\min & G^{M}(q, A ; p, a)=-E^{M}=\sum_{i=1}^{m}\left(c_{m}+T_{i}-c_{p}\right) q_{i}+A+\sum_{i=1}^{m} t_{i} a_{i}+S^{M}+\sum_{i=1}^{m}\left(H_{i}^{R} \int_{0}^{z_{i}}\left(q_{i}-D_{i}\right) f\left(\xi_{i}\right) \mathrm{d} \xi_{i}+L_{i}^{R} \int_{z_{i}}^{+\infty}\left(D_{i}-q_{i}\right) f\left(\xi_{i}\right) \mathrm{d} \xi_{i}\right) \\
\text { s.t. } & \sum_{i=1}^{m} q_{i} \leq P, \quad A \geq 0 .
\end{array}
$$

$\left(p_{i}, a_{i}\right)$ is the solution of the following optimization problem:

$$
\begin{array}{ll}
\min & G_{i}^{R}\left(p_{i}, a_{i} ; q_{i}, A\right)=-E_{i}^{R}=\left(I_{i}-p_{i}\right)\left(\int_{0}^{z_{i}} D_{i} f\left(\xi_{i}\right) d \xi_{i}+\int_{z_{i}}^{+\infty} q_{i} f\left(\xi_{i}\right) d \xi_{i}\right)+c_{p} q_{i}+\left(1-t_{i}\right) a_{i}+S_{i}^{R} \\
\text { s.t. } & p_{i} \geq c_{p}+I_{i}, \quad a_{i} \geq 0, i=1,2, \ldots, m .
\end{array}
$$


Remark 1. Different from an ordinary bilevel programming problem, Model (18) contains two objective functions with complicated definite integrals, which are associated with the unknown decision variables. Thus, how to develop efficient algorithms, other than heuristic algorithms, to find the equilibrium point of Model (18) is an interesting issue.

\section{Reformulation of Bilevel Programming Model}

It is well known that (18) is a bilevel mathematical programming problem. With some mild assumptions, any twolevel mathematical programming problem can be reformulated as a mathematical program with complementarity constraints (MPCC) (see, e.g., [43, 44]). In this section, we will transform the bilevel programming problem into an
MPCC based on the Karush-Kuhn-Tucker (KKT) conditions of the lower-level optimization model.

For the lower-level optimization model in (18), let $\lambda_{i}$ and $\gamma_{i}$ be the Lagrangian multipliers corresponding to the two types of constraints in Model (6). Then, the Lagrangian function of the lower-level optimization model is written as

$$
\begin{aligned}
L_{i}\left(p_{i}, a_{i} ; \lambda_{i}, \gamma_{i}\right)= & \left(I_{i}-p_{i}\right)\left(\int_{0}^{z_{i}} D_{i} f\left(\xi_{i}\right) \mathrm{d} \xi_{i}\right. \\
& \left.+\int_{z_{i}}^{+\infty} q_{i} f\left(\xi_{i}\right) \mathrm{d} \xi_{i}\right)+c_{p} q_{i}+\left(1-t_{i}\right) a_{i} \\
& +S_{i}^{R}-\lambda_{i}\left(p_{i}-c_{p}-I_{i}\right)-\gamma_{i} a_{i} .
\end{aligned}
$$

To simplify the calculation, denote

$$
\left\{\begin{array}{l}
p_{i}^{\prime}=p_{i}-I_{i}-c_{p}, \\
a_{i}^{\prime}=a_{i}, \\
d_{i}^{\prime}=\left(\alpha-\beta_{i}\left(p_{i}^{\prime}+I_{i}+c_{p}\right)+\sum_{j \neq i} \rho_{i j} p_{j}\right)\left(k+k_{m} \sqrt{A}+k_{i} \sqrt{a_{i}^{\prime}}-\sum_{j \neq i} \tau_{i j} \sqrt{a_{j}}\right), \\
z_{i}^{\prime}=q_{i}-d_{i}^{\prime} .
\end{array}\right.
$$

Then, $L_{i}$ has a more compact form:

$$
\begin{aligned}
L_{i}= & -\left(p_{i}^{\prime}+c_{p}\right)\left(\int_{0}^{z_{i}^{\prime}} D_{i}^{\prime} f\left(\xi_{i}\right) \mathrm{d} \xi_{i}+\int_{z_{i}^{\prime}}^{+\infty} q_{i} f\left(\xi_{i}\right) \mathrm{d} \xi_{i}\right) \\
& +c_{p} q_{i}+\left(1-t_{i}\right) a_{i}^{\prime}+S_{i}^{R}-\lambda_{i} p_{i}^{\prime}-\gamma_{i} a_{i}^{\prime} .
\end{aligned}
$$

In virtue of (22), any optimal solution of the lower-level problem satisfies the following KKT conditions with suitable constraint qualification $[43,44]$ :

$$
\left\{\begin{array}{l}
\left(k+k_{m} \sqrt{A}+k_{i} \sqrt{a_{i}^{\prime}}-\sum_{j \neq i} \tau_{i j} \sqrt{a_{j}}\right)\left(\beta_{i}\left(2\left(p_{i}^{\prime}+c_{p}\right)+I_{i}\right)-\alpha\right) \int_{0}^{z_{i}^{\prime}} f\left(\xi_{i}\right) \mathrm{d} \xi_{i}, \\
-\int_{0}^{z_{i}^{\prime}} \xi_{i} f\left(\xi_{i}\right) \mathrm{d} \xi_{i}-\int_{z_{i}^{\prime}}^{+\infty} q_{i} f\left(\xi_{i}\right) \mathrm{d} \xi_{i}-\lambda_{i}=0, \\
-\frac{k_{i}}{2 \sqrt{a_{i}^{\prime}}}\left(p_{i}^{\prime}+c_{p}\right)\left(\alpha-\beta_{i}\left(p_{i}^{\prime}+I_{i}+c_{p}\right)+\sum_{j \neq i} \rho_{i j} \sqrt{p_{j}}\right) \int_{0}^{z_{i}^{\prime}} f\left(\xi_{i}\right) \mathrm{d} \xi_{i}+1-t_{i}-\gamma_{i}=0, \\
\lambda_{i} \geq 0, p_{i}^{\prime} \geq 0, \lambda_{i} p_{i}^{\prime}=0, \\
\gamma_{i} \geq 0, a_{i}^{\prime} \geq 0, \gamma_{i} a_{i}^{\prime}=0 .
\end{array}\right.
$$


Set

$$
\left\{\begin{array}{l}
y_{i}=\left(\begin{array}{c}
p_{i}^{\prime} \\
a_{i}^{\prime}
\end{array}\right), \\
f_{1}\left(y_{i}\right)=\left(k+k_{m} \sqrt{A}+k_{i} \sqrt{a_{i}^{\prime}}-\sum_{j \neq i} \tau_{i j} \sqrt{a_{j}}\right)\left(\beta_{i}\left(2\left(p_{i}^{\prime}+c_{p}\right)+I_{i}\right)-\alpha\right) \int_{0}^{z_{i}^{\prime}} f\left(\xi_{i}\right) \mathrm{d} \xi_{i}, \\
-\int_{0}^{z_{i}^{\prime}} \xi_{i} f\left(\xi_{i}\right) \mathrm{d} \xi_{i}-\int_{z_{i}^{\prime}}^{+\infty} q_{i} f\left(\xi_{i}\right) \mathrm{d} \xi_{i}, \\
f_{2}\left(y_{i}\right)=-\frac{k_{i}}{2 \sqrt{a_{i}^{\prime}}}\left(p_{i}^{\prime}+c_{p}\right)\left(\alpha-\beta_{i}\left(p_{i}^{\prime}+I_{i}+c_{p}\right)+\sum_{j \neq i} \rho_{i j} \sqrt{p_{j}}\right) \int_{0}^{z_{i}^{\prime}} f\left(\xi_{i}\right) \mathrm{d} \xi_{i}+1-t_{i}, \\
F\left(y_{i}\right)=\left(\begin{array}{c}
f_{1}\left(y_{i}\right) \\
f_{2}\left(y_{i}\right)
\end{array}\right) .
\end{array}\right.
$$

Then, the KKT condition (23) is rewritten as the following standard complementarity problem:

$$
\begin{aligned}
y_{i} & \geq 0, \\
F\left(y_{i}\right) & \geq 0, \\
y_{i}^{T} F\left(y_{i}\right) & =0, \\
i & =1,2, \ldots, m .
\end{aligned}
$$

Clearly, (25) is involved in the unknown upper-level decision variables.

Remark 2. Due to the presence of multiple retailers who make decisions simultaneously, the retailers' decisions affect each other's objective functions/utilities. Thus, the lowerlevel problem asks for finding a Nash equilibrium in the follower's game for any given decision of the manufacturer. In general, Nash equilibrium problems may admit many equilibria. In this paper, by a KKT reformulation, it is supposed that all the followers collectively choose an equilibrium that maximizes the leader's (the manufacturer's) utility.

Remark 3. Since the constraints in the lower-level problem are only associated with simple bound constraints and are not related to the upper-level decision variables, it is easy to see that linear independence constraint qualification (LICQ) holds at any point of its feasible region. Thus, each upperlevel solution satisfies the KKT conditions $(25)$. In [46, 47], some sufficient conditions were given to ensure that a locally optimal solution of the original bilevel programming problem translates bijectively into a locally optimal solution of the associated single-level KKT-based reformulation.
As done in [44], we further replace (23) with the following smooth inequality constraints:

$$
\begin{aligned}
y_{i} & \geq 0, \\
F\left(y_{i}\right) & \geq 0, \\
\Phi_{\varepsilon}\left(y_{i}\right) & \leq 0, \\
i & =1,2, \ldots, m,
\end{aligned}
$$

where

$$
\begin{aligned}
\Phi_{\varepsilon}\left(y_{i}\right) & =\left(\begin{array}{c}
\phi_{\varepsilon, 1}\left(y_{i}\right) \\
\phi_{\varepsilon, 2}\left(y_{i}\right)
\end{array}\right), \\
\phi_{\varepsilon, 1}\left(y_{i}\right) & =\frac{1}{2}\left(p_{i}^{\prime}+f_{1}\left(y_{i}\right)-\psi_{\varepsilon}\left(p_{i}^{\prime}-f_{1}\left(y_{i}\right)\right)\right), \\
\phi_{\varepsilon, 2}\left(y_{i}\right) & =\frac{1}{2}\left(a_{i}^{\prime}+f_{2}\left(y_{i}\right)-\psi_{\varepsilon}\left(a_{i}^{\prime}-f_{2}\left(y_{i}\right)\right)\right), \\
\psi_{\varepsilon}(t) & =\frac{2 t}{\pi} \arctan \left(\frac{t}{\varepsilon}\right) .
\end{aligned}
$$

Consequently, the bilevel programming model (18) is reformulated as a standard smooth optimization problem:

$$
\begin{array}{ll}
\min & G_{m}(x), \\
\text { s.t. } & \sum_{i=1}^{m} q_{i} \leq P \\
& A \geq 0 \\
& y_{i} \geq 0, F\left(y_{i}\right) \geq 0, \Phi_{\varepsilon}\left(y_{i}\right) \leq 0, i=1,2, \ldots, m,
\end{array}
$$


where

$$
\left\{\begin{array}{l}
x=\left(q, A, p^{\prime}, a^{\prime}\right), \\
G_{m}(x)=\sum_{i=1}^{m}\left(c_{m}+T_{i}-c_{p}\right) q_{i}+A+\sum_{i=1}^{m} t_{i} a_{i}^{\prime}+S^{M}+\sum_{i=1}^{m}\left(H_{i}^{R} \int_{0}^{z_{i}^{\prime}}\left(q_{i}-D_{i}^{\prime}\right) f\left(\xi_{i}\right) \mathrm{d} \xi_{i}+L_{i}^{R} \int_{z_{i}^{\prime}}^{+\infty}\left(D_{i}^{\prime}-q_{i}\right) f\left(\xi_{i}\right) \mathrm{d} \xi_{i}\right) .
\end{array}\right.
$$

Remark 4. Although Model (28) is a smooth nonlinear optimization problem, it is a difficult task to evaluate the objective function because it is associated with computing the complicated integrals being dependent on the unknown decision variables in the case that the demand is the continuous random variable. Generally, standard optimization techniques or the existing software packages such as MATLAB, CPLEX, and Lingo cannot be directly used to solve Model (28).

Remark 5. For a complicated optimization model, heuristic algorithms are often designed to approximate its solution. However, any heuristic algorithm needs more expensive computation cost due to the random search of iterative points, as well as being difficult to establish its convergence theory. One of our research intentions in this paper is to develop an efficient algorithm to solve (28) based on the gradient information of the objective and constraints.

\section{Development of Gradient-Based Algorithm}

Heuristic algorithms or analytic methods such as the backward induction procedure in [4] are the popular methods available in the literature to solve the bilevel programming problems. However, on the one hand, there does not exist any analytic method to solve Model (28) owing to its complexity. On the other hand, numerical efficiency of any heuristic algorithm for solving Model (28) is often not satisfactory since no analytic property of Model (28) is employed to search for the optimal solution. For these mentioned reasons, we attempt to develop an efficient algorithm to solve Model (28) in this section, similar to the idea of [35]. Actually, it has been shown that the algorithm developed in [35] is efficient to solve the stochastic model of global supply chain management problem by numerical experiments, especially in comparison with the heuristic algorithm.

Basically, similar to the way presented in [35], we first approximate Model (28) by a series of linear programming problems based on the gradient information of the objective function and constraints. Then, by solving the linearized subproblem, we will obtain a search direction at any given approximate solution of Model (28). Finally, by a suitable line search rule, a step length along the search direction is computed such that a better approximate solution of Model (28) is obtained.

By directly taking the derivative, we get the following results.

Proposition 1. Let $f_{1}\left(y_{i}\right)$ and $f_{2}\left(y_{i}\right)$ be defined in (24). Then,

$$
\begin{aligned}
\frac{\partial f_{1}\left(y_{i}\right)}{\partial q_{i}}= & \left(k+k_{m} \sqrt{A}+k_{i} \sqrt{a_{i}^{\prime}}-\sum_{j \neq i} \tau_{i j} \sqrt{a_{j}}\right)\left(2 \beta_{i}\left(p_{i}^{\prime}+c_{p}+\frac{1}{2} I_{i}\right)-\alpha\right) f\left(z_{i}^{\prime}\right) \\
& +\left(d_{i}^{\prime}-2 q_{i}\right) f\left(z_{i}^{\prime}\right)+\int_{z_{i}^{\prime}}^{+\infty} f\left(\xi_{i}\right) \mathrm{d} \xi_{i}, \\
\frac{\partial f_{1}\left(y_{i}\right)}{\partial A}= & \left(2 \beta_{i}\left(p_{i}^{\prime}+c_{p}+\frac{1}{2} I_{i}\right)-\alpha\right) \frac{k_{m}}{2 \sqrt{A}} \int_{0}^{z_{i}^{\prime}} f\left(\xi_{i}\right) \mathrm{d} \xi_{i} \\
& -\beta_{i}\left(p_{i}^{\prime}+c_{p}\right) d_{i}^{\prime} \frac{k_{m}}{2 \sqrt{A}} f\left(z_{i}^{\prime}\right), \\
\frac{\partial f_{1}\left(y_{i}\right)}{\partial p_{i}^{\prime}}= & \left(d_{i}^{\prime}+\beta_{i}\left(k+k_{m} \sqrt{A}+k_{i} \sqrt{a_{i}^{\prime}}-\sum_{j \neq i} \tau_{i j} \sqrt{a_{j}}\right)^{2}\left(2 \beta_{i}\left(p_{i}^{\prime}+c_{p}+\frac{1}{2} I_{i}\right)-\alpha\right)\right) f\left(z_{i}^{\prime}\right) \\
& +2 \beta_{i}\left(k+k_{m} \sqrt{A}+k_{i} \sqrt{a_{i}^{\prime}}-\sum_{j \neq i} \tau_{i j} \sqrt{a_{j}}\right) \int_{0}^{z_{i}^{\prime}} f\left(\xi_{i}\right) \mathrm{d} \xi_{i},
\end{aligned}
$$




$$
\begin{aligned}
& \frac{\partial f_{1}\left(y_{i}\right)}{\partial a_{i}^{\prime}}=\left(2 \beta_{i}\left(p_{i}^{\prime}+c_{p}+\frac{1}{2} I_{i}\right)-\alpha\right) \frac{k_{i}}{2 \sqrt{a_{i}^{\prime}}} \int_{0}^{z_{i}^{\prime}} f\left(\xi_{i}\right) \mathrm{d} \xi_{i} \\
& -\beta_{i}\left(p_{i}^{\prime}+c_{p}\right) d_{i}^{\prime} \frac{k_{i}}{2 \sqrt{a_{i}^{\prime}}} f\left(z_{i}^{\prime}\right) \\
& \frac{\partial f_{2}\left(y_{i}\right)}{\partial q_{i}}=-\frac{k_{i}}{2 \sqrt{a_{i}^{\prime}}}\left(p_{i}^{\prime}+c_{p}\right)\left(\alpha-\beta_{i}\left(p_{i}^{\prime}+c_{p}+I_{i}\right)\right) f\left(z_{i}^{\prime}\right), \\
& \frac{\partial f_{2}\left(y_{i}\right)}{\partial A}=\frac{k_{i} k_{m}}{4 \sqrt{A a_{i}^{\prime}}}\left(p_{i}^{\prime}+c_{p}\right)\left(\alpha-\beta_{i}\left(p_{i}^{\prime}+c_{p}+I_{i}\right)\right)^{2} f\left(z_{i}^{\prime}\right), \\
& \frac{\partial f_{2}\left(y_{i}\right)}{\partial p_{i}^{\prime}}=\frac{k_{i}}{2 \sqrt{a_{i}^{\prime}}}\left(2 \beta_{i}\left(p_{i}^{\prime}+c_{p}+\frac{1}{2} I_{i}\right)-\alpha\right) \int_{0}^{z_{i}^{\prime}} f\left(\xi_{i}\right) \mathrm{d} \xi_{i}-\frac{k_{i}}{2 \sqrt{a_{i}^{\prime}}} \beta_{i}\left(p_{i}^{\prime}+c_{p}\right) d_{i}^{\prime} f\left(z_{i}^{\prime}\right), \\
& \frac{\partial f_{2}\left(y_{i}\right)}{\partial a_{i}^{\prime}}=\frac{k_{i} a_{i}^{\prime}(-3 / 2)}{4}\left(p_{i}^{\prime}+c_{p}\right)\left(\alpha-\beta_{i}\left(p_{i}^{\prime}+c_{p}+I_{i}\right)+\sum_{j \neq i} \rho_{i j} \sqrt{p_{j}}\right) \int_{0}^{z_{i}^{\prime}} f\left(\xi_{i}\right) \mathrm{d} \xi_{i} \\
& +\frac{k_{i}^{2}}{4 a_{i}^{\prime}}\left(p_{i}^{\prime}+c_{p}\right)\left(\alpha-\beta_{i}\left(p_{i}^{\prime}+c_{p}+I_{i}\right)+\sum_{j \neq i} \rho_{i j} \sqrt{p_{j}}\right)^{2} f\left(z_{i}^{\prime}\right) .
\end{aligned}
$$

Proposition 2. Let $\phi_{\varepsilon, 1}\left(y_{i}\right)$ and $\phi_{\varepsilon, 2}\left(y_{i}\right)$ be defined in (27).

Then,

$$
\begin{aligned}
& \frac{\partial \phi_{\varepsilon, 1}\left(y_{i}\right)}{\partial q_{i}}=\frac{1}{2} \frac{\partial f_{1}}{\partial q_{i}}+\frac{\left(\partial f_{1} / \partial q_{i}\right) \arctan \left(\left(p_{i}^{\prime}-f_{1}\right) / \varepsilon\right)}{\pi}+\frac{\varepsilon\left(p_{i}^{\prime}-f_{1}\right)\left(\partial f_{1} / \partial q_{i}\right)}{\pi\left(\varepsilon^{2}+\left(p_{i}^{\prime}-f_{1}\right)^{2}\right)} \\
& \frac{\partial \phi_{\varepsilon, 1}\left(y_{i}\right)}{\partial A}=\frac{1}{2} \frac{\partial f_{1}}{\partial A}+\frac{\left(\partial f_{1} / \partial A\right) \arctan \left(\left(p_{i}^{\prime}-f_{1}\right) / \varepsilon\right)}{\pi}+\frac{\varepsilon\left(p_{i}^{\prime}-f_{1}\right)\left(\partial f_{1} / \partial A\right)}{\pi\left(\varepsilon^{2}+\left(p_{i}^{\prime}-f_{1}\right)^{2}\right)} \\
& \frac{\partial \phi_{\varepsilon, 1}\left(y_{i}\right)}{\partial p_{i}^{\prime}}=\frac{1}{2}\left(1+\frac{\partial f_{1}}{\partial p_{i}^{\prime}}\right)-\left(1-\frac{\partial f_{1}}{\partial p_{i}^{\prime}}\right) \frac{\left(\arctan \left(\left(p_{i}^{\prime}-f_{1}\right) / \varepsilon\right)\right)}{\pi}-\frac{\varepsilon\left(p_{i}^{\prime}-f_{1 i}\right)\left(1-\left(\partial f_{1} / \partial p_{i}^{\prime}\right)\right)}{\pi\left(\varepsilon^{2}+\left(p_{i}^{\prime}-f_{1}\right)^{2}\right)} \\
& \frac{\partial \phi_{\varepsilon, 1}\left(y_{i}\right)}{\partial a_{i}^{\prime}}=\frac{1}{2} \frac{\partial f_{1}}{\partial a_{i}^{\prime}}+\frac{\left(\partial f_{1} / \partial a_{i}^{\prime}\right) \arctan \left(\left(p_{i}^{\prime}-f_{1}\right) / \varepsilon\right)}{\pi}+\frac{\varepsilon\left(p_{i}^{\prime}-f_{1}\right)\left(\partial f_{1} / \partial a_{i}^{\prime}\right)}{\pi\left(\varepsilon^{2}+\left(p_{i}^{\prime}-f_{1}\right)^{2}\right)} \\
& \frac{\partial \phi_{\varepsilon, 2}\left(y_{i}\right)}{\partial q_{i}}=\frac{1}{2} \frac{\partial f_{2}}{\partial q_{i}}+\frac{\left(\partial f_{2} / \partial q_{i}\right) \arctan \left(\left(a_{i}^{\prime}-f_{2}\right) / \varepsilon\right)}{\pi}+\frac{\varepsilon\left(a_{i}^{\prime}-f_{2}\right)\left(\partial f_{2} / \partial q_{i}\right)}{\pi\left(\varepsilon^{2}+\left(a_{i}^{\prime}-f_{2}\right)^{2}\right)} \\
& \frac{\partial \phi_{\varepsilon, 2}\left(y_{i}\right)}{\partial A}=\frac{1}{2} \frac{\partial f_{2}}{\partial A}+\frac{\left(\partial f_{2} / \partial A\right) \arctan \left(\left(a_{i}^{\prime}-f_{2}\right) / \varepsilon\right)}{\pi}+\frac{\varepsilon\left(a_{i}^{\prime}-f_{2}\right)\left(\partial f_{2} / \partial A\right)}{\pi\left(\varepsilon^{2}+\left(a_{i}^{\prime}-f_{2}\right)^{2}\right)} \\
& \frac{\partial \phi_{\varepsilon, 2}\left(y_{i}\right)}{\partial p_{i}^{\prime}}=\frac{1}{2} \frac{\partial f_{2}}{\partial p_{i}^{\prime}}+\frac{\left(\partial f_{2} / \partial p_{i}^{\prime}\right) \arctan \left(\left(a_{i}^{\prime}-f_{2}\right) / \varepsilon\right)}{\pi}+\frac{\varepsilon\left(a_{i}^{\prime}-f_{2}\right)\left(\partial f_{2 i} / \partial p_{i}^{\prime}\right)}{\pi\left(\varepsilon^{2}+\left(a_{i}^{\prime}-f_{2}\right)^{2}\right)} \\
& \frac{\partial \phi_{\varepsilon, 2}\left(y_{i}\right)}{\partial a_{i}^{\prime}}=\frac{1}{2}\left(1+\frac{\partial f_{2}}{\partial a_{i}^{\prime}}\right)-\left(1-\frac{\partial f_{2}}{\partial a_{i}^{\prime}}\right) \frac{\arctan \left(\left(a_{i}^{\prime}-f_{2}\right) / \varepsilon\right)}{\pi}-\frac{\varepsilon\left(a_{i}^{\prime}-f_{2}\right)\left(1-\left(\partial f_{2} / \partial a_{i}^{\prime}\right)\right)}{\pi\left(\varepsilon^{2}+\left(a_{i}^{\prime}-f_{2}\right)^{2}\right)}
\end{aligned}
$$


Proposition 3. Let $G_{m}(x)$ be defined in (29). Then,

$$
\begin{aligned}
\frac{\partial G_{m}(x)}{\partial q_{i}}= & c_{m}+T_{i}-c_{p}+H_{i}^{R} \int_{0}^{z_{i}^{\prime}} f\left(\xi_{i}\right) \mathrm{d} \xi_{i}-L_{i}^{R} \int_{z_{i}^{\prime}}^{+\infty} f\left(\xi_{i}\right) \mathrm{d} \xi_{i}, \\
\frac{\partial G_{m}(x)}{\partial A}= & 1+L_{i}^{R}\left(\alpha-\beta_{i}\left(p_{i}^{\prime}+c_{p}+I_{i}\right)+\sum_{j \neq i} \rho_{i j} \sqrt{p_{j}}\right) \frac{k_{m}}{2 \sqrt{A}} \\
& -\left(H_{i}^{R}+L_{i}^{R}\right)\left(\alpha-\beta_{i}\left(p_{i}^{\prime}+c_{p}+I_{i}\right)+\sum_{j \neq i} \rho_{i j} \sqrt{p_{j}}\right) \frac{k_{m}}{2 \sqrt{A}} \int_{0}^{z_{i}^{\prime}} f\left(\xi_{i}\right) \mathrm{d} \xi_{i}, \\
\frac{\partial G_{m}(x)}{\partial p_{i}^{\prime}}= & H_{i}^{R} \beta_{i}\left(k+k_{m} \sqrt{A}+k_{i} \sqrt{a_{i}^{\prime}}-\sum_{j \neq i} \tau_{i j} \sqrt{a_{j}}\right), \\
\frac{\partial G_{m}(x)}{\partial a_{i}^{\prime}}= & t_{i}+L_{i}^{R}\left(\alpha-\beta_{i}\left(p_{i}^{\prime}+c_{p}+I_{i}\right)+\sum_{j \neq i} \rho_{i j} \sqrt{p_{j}}\right) \\
& -\left(H_{i}^{R}+L_{i}^{R}\right)\left(\alpha-\beta_{i}\left(p_{i}^{\prime}+c_{p}+I_{i}\right)+\sum_{j \neq i} \rho_{i j} \sqrt{p_{j}}\right) \frac{k_{i}}{2 \sqrt{a_{i}^{\prime}}} \int_{0}^{z_{i}^{\prime}} f\left(\xi_{i}\right) \mathrm{d} \xi_{i} .
\end{aligned}
$$

Remark 6. For a given point $x_{k}$, Propositions 1 and 2 are useful to compute the gradients of $f_{1}\left(y_{i}\right), f_{2}\left(y_{i}\right), \phi_{\varepsilon, 1}\left(y_{i}\right)$, and $\phi_{\varepsilon, 2}\left(y_{i}\right)$, being referred to as $\nabla f_{1}\left(y_{i}\right), \nabla f_{2}\left(y_{i}\right), \nabla \phi_{\varepsilon, 1}\left(y_{i}\right)$, and $\nabla \phi_{\varepsilon, 2}\left(y_{i}\right)$, respectively. Thus, the gradients of $F\left(y_{i}\right)$ and $\Phi_{\varepsilon}\left(y_{i}\right)$, being referred to as $\nabla F\left(y_{i}\right)$ and $\nabla \Phi_{\varepsilon}\left(y_{i}\right)$, are obtained, respectively. Proposition 3 presents the gradient of the objective function at $x_{k}$.

In view of Propositions 1-3, we can construct a linear approximate model of (28) at a given point $x_{k}$. Specifically, denote $d=x-x_{k}$; then any nonzero solution of the following linear programming problem determines a feasible descent direction of Model (28) at $x_{k}$ (see [48]):

$$
\begin{aligned}
& \min z, \\
& \text { s.t. } \quad \nabla G_{m}\left(x_{k}\right)^{T} d-z \leq 0 \\
& \sum_{i=1}^{m} q_{i}^{k}+d_{q_{i}}-z \leq P, \\
&(D F(x)) \quad A^{k}+d_{A}+z \geq 0, y_{i}^{k}+d_{y_{i}}+z \geq 0, \\
& F\left(y_{i}^{k}\right)+\nabla F\left(y_{i}^{k}\right)^{T} d+z \geq 0, \\
& \Phi_{\varepsilon}\left(y_{i}^{k}\right)+\nabla \Phi_{\varepsilon}\left(y_{i}^{k}\right)^{T} d-z \leq 0, \\
&\|d\|_{\infty} \leq 1, \quad i=1,2, \ldots, m,
\end{aligned}
$$

where $d_{q_{i}}, d_{A}$, and $d_{y_{i}}$ are the components of $d$ corresponding to the variables $q_{i}, A$, and $y_{i}$, respectively. Thus, (33) is called the linearized subproblem in solving Model (28). Determination of a search direction by solving (33) is one of the main steps in the following Algorithm 1.

\section{Algorithm 1. (Modified Topkis-Veinott Algorithm)}

Step 0. Choose an initial point $x_{0} \in D$ and $z_{0}$ large enough. $\epsilon_{1}$ $>0$ is a given constant. Set $k:=0$.
Step 1. If $\left|z_{k}\right|<\epsilon_{1}$, the algorithm stops. Otherwise, go to Step 2.

Step 2. For the given $x_{k}$, solve the subproblem (33). Its solution is referred to as $d_{k}$.

Step 3. With $d_{k}$, compute $\alpha_{k}^{\max }=\max \left\{\alpha \mid x_{k}+\alpha d_{k} \in D\right\}$. Then, find an optimal step length by solving the following single-variable optimization model:

$$
\min _{0 \leq \alpha \leq \alpha_{k}^{\max }} G_{m}\left(x_{k}+\alpha d_{k}\right)
$$

Denote by $\alpha_{k}$ the optimal solution of (34).

Step 4. Set $x_{k+1}:=x_{k}+\alpha_{k} d_{k}$. Update $k:=k+1$. Return to Step 1 .

Remark 7. Since it is often difficult to calculate the optimal step length $\alpha_{k}$ in Step 3 of Algorithm 1, instead of solving problem (34), we find $\alpha_{k}=\eta^{i} \alpha_{k}^{\max }$ satisfying the following inequality:

$$
G_{m}\left(x_{k}+\alpha_{k} d_{k}\right) \leq G_{m}\left(x_{k}\right)+\delta \alpha_{k} \nabla G_{m}\left(x_{k}\right)^{T} d_{k}
$$

where $i$ is the largest integer such that the above inequality holds; $\eta, \delta \in(0,1)$ are two given constants.

Remark 8. Algorithm 1 can be regarded as a special version of the Topkis-Veinott method in $[48,49]$ as it is used to solve Model (28), which is complicated. Unlike more popular SQP-type algorithms for solving smooth nonlinear constrained optimization problems, the Topkis-Veinott method does not require the second-order information of the objective function to generate a search direction. As done in Step 2 of Algorithm 1, we obtain the search direction $d_{k}$ by solving the linearly approximate Model (33). Actually, for 
Problem (28), it is difficult to obtain the second-order information of its objective function. Thus, the SQP-type algorithms are not suited for solving Model (28).

Remark 9. Another advantage of Algorithm 1 is that it can globally converge to a Fritz John point even if Model (28) has no KKT point (see [49]). In other words, Algorithm 1 may work well for solving Model (28) in the case that the SQPtype methods do not.

From Propositions $1-3$, it is clear that the complexity of Model (28) does not eliminate its first-order smoothness. Therefore, similar to the proofs in $[48,49]$ for the TopkisVeinott method, we can prove the following property of Algorithm 1.

Theorem 1. Let $\left\{x_{k}\right\}$ be a sequence generated by Algorithm 1 in solving Model (28). Then, any accumulation point of $\left\{x_{k}\right\}$ is a Fritz John point of (28).

\section{Sensitivity Analysis}

In this section, we intend to investigate the impacts of some primary model parameters on decision-making by sensitivity analysis.

Consider a VMI supply chain with one manufacturer and two competitive retailers. Similar to [4], we choose the values of the parameters in Model (28) as follows:

$$
\left\{\begin{array}{l}
m=2, \alpha=35, \beta_{i}=2, \rho_{i j}=1.5, K=10, k_{m}=0.5, k_{i}=1.5, \\
\tau_{i j}=0.8, t_{i}=0.7, H_{i}^{R}=12, L_{i}^{R}=500, c_{p}=100, c_{m}=20, \\
S^{M}=20, S_{i}^{R}=10, T_{i}=5, I_{i}=2, P=10000, \mu_{i}=1, \sigma_{i}=1 .
\end{array}\right.
$$

Our main concerns include the following: (1) What are the impacts of the market parameters $\left(\beta_{i}, \rho_{i j}, k_{i}\right)$ on the profit of retailers and the demand? (2) What are the impacts of the uncertainty in the demand function on the profit of retailers? (3) What is the value of participation rate $t_{i}$ (the advertising expenditure ratio of retailer $i$ to that born by the manufacturer (\$/unit)) as the manufacturer's profit reaches the maximum? (4) What are the impacts of the advertising coefficient of sensitivity on the participation rate $t_{i}$ ? (5) What are the impacts of the manufacturing cost $c_{m}$ and shortage $\operatorname{cost} L_{i}^{R}$ on the manufacturer's profit?

All the computer codes of Algorithm 1 are written in MATLAB 2012b and run on a personal computer with the operation system of Windows 7, 1.8 GHZ CPU, and 4.00 GB RAM.

6.1. Impacts of Sensitivity Coefficients on Demand. Since one of the main contributions in this paper is the construction of the new demand function given by (1) and (2), we first reveal what are the underlying effects of competition between the different retailers on the demand by numerical method.

For one retailer, we change its own price coefficient of sensitivity and that of its competitors with a step size 0.2 ; then we solve Model (28) by Algorithm 1 to compute the corresponding values of demand. In Figures 1(a) and 1(b), we present the dependence of the demand on the concerned retailer's retail price coefficient of sensitivity and that of its competitors.

6.2. Impacts of Critical Model Parameters on Vendors. Since the manufacturer is the leader of the VMI system, we concern how his optimal decision and the corresponding profit are affected by the model parameters. In particular, we want to study what are the critical roles of those parameters in the new demand function given by (1) and (2).

In Figure 2, we plot the impacts of the advertising coefficients of sensitivity on the participation rate, including the sensitivity coefficient $\left(k_{m}\right)$ of the manufacturer's advertising expenditure and that $\left(k_{i}\right)$ of the retailers' advertising expenditure.

From Figure 2, it follows that the advertising sensitivity coefficients of the manufacturer and retailer are critical factors that affect the decision-making of VMI system. Actually, higher advertising sensitivity results in greater participation rate, and the manufacturer's participation rate depends more on its own advertising sensitivity coefficient. In other words, in the case that the effect of the retailer's advertising is higher than that of manufacturer's effort; lower participation rate is preferred by the manufacturer. Just like intuitive judgement, Figure 2 also demonstrates that lower values of $k_{m}$ and $k_{i}$ result in smaller participation rate.

We next analyze how the manufacturer's profit is affected by the ratio of advertising investment done by the retailers and that by the manufacturers. Figure 3 presents the numerical results.

From Figure 3, it follows that the impact of the ratio of advertising expenditure between retailers and manufacturers on profits meets the law of diminishing marginal effect [50]. Actually, in the initial stage, when the manufacturer continuously increases the retailing advertising expenditure, its profit also increases, but when the retailing advertising investment increases to certain threshold $\left(t_{i} \approx 0.7\right.$ in Figure 3), the profit declines. In short, the margin for the ratio of advertising investments spent by the retailers and the manufacturer diminishes at a critical ratio. Clearly, for the manufacturer (the leader of the VMI system), he can find this optimal retailing advertising ratio by the aid of the developed model and algorithm in this paper.

In Figure 4, we further plot the effect of participation rate, $t_{i}$, on the ratio of the maximal profit to the total cost.

Figure 4 demonstrates the following:

(1) The ratio of the manufacturer's maximal profit to the total cost decreases with an increasing $t_{i}$, while the conclusion is opposite for the retailers.

(2) For the VMI system, in line with the principle of the highest utilization of capital, the manufacturer is willing to choose the smaller values of $t_{i}$, but the retailers hope that it is as big as possible. In light of our model and algorithm in this paper, an optimal participation rate can be obtained by choosing the intersection point of the cost-profit curves given for the manufacturer and the retailers. 


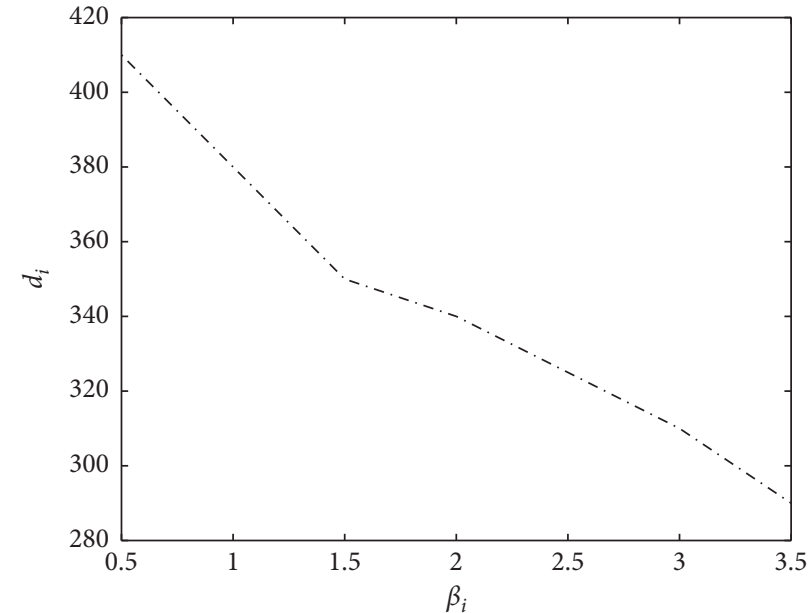

(a)

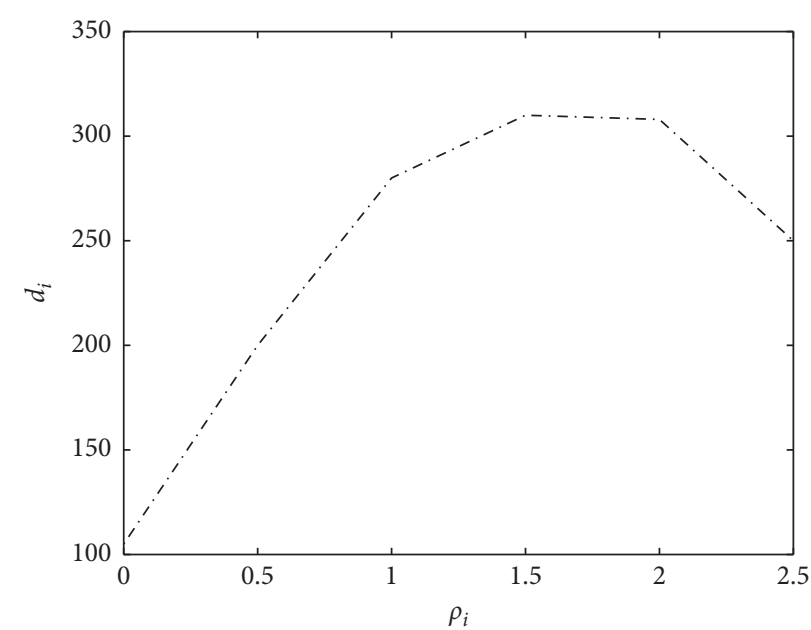

(b)

FIGURE 1: Impacts of price sensitivity coefficients on demand. (a) The concerned retailer's price sensitivity. (b) The competitor's price sensitivity.

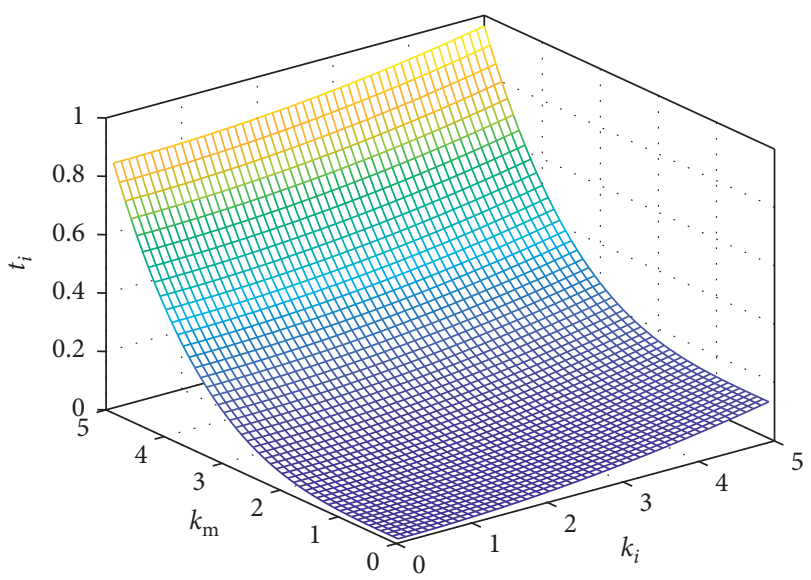

FIGURE 2: Impacts of advertising sensitivity coefficients on participation rate.

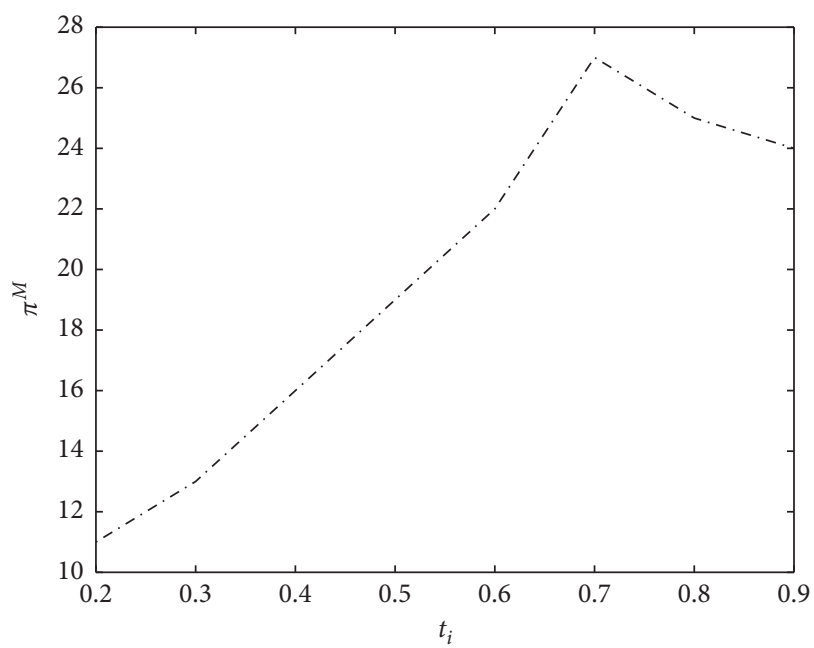

FIGURE 3: Impacts of advertising ratio on manufacturer's profit.

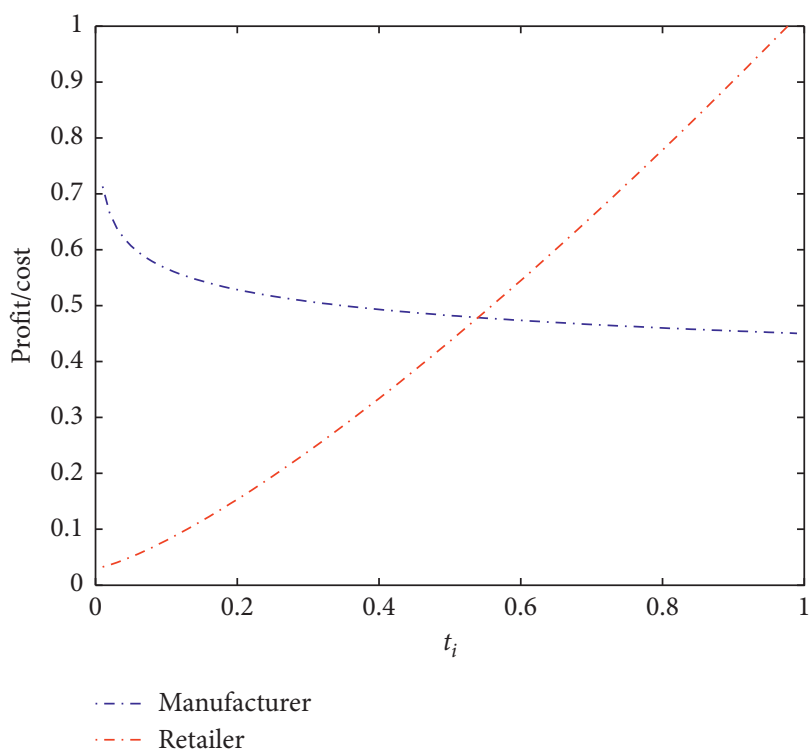

FIgURE 4: Effect of participation rate on the ratio of profit to cost.

We are in a position to study the impacts of unit operational costs.

By changing the unit manufacturing cost and the unit holding cost with a step size of 0.5 , we attempt to explore how they affect the total profit of the manufacturer, the leader of the VMI system. The obtained numerical results are described in Figure 5.

From Figure 5, we conclude the following:

(1) The manufacturer's profit is (approximately) linearly decreasing as the unit manufacturing cost (the main components of the direct cost) increases (see Figure 5(a)).

(2) As the unit holding cost (the main components of the indirect costs) increases, the profit earned by the 


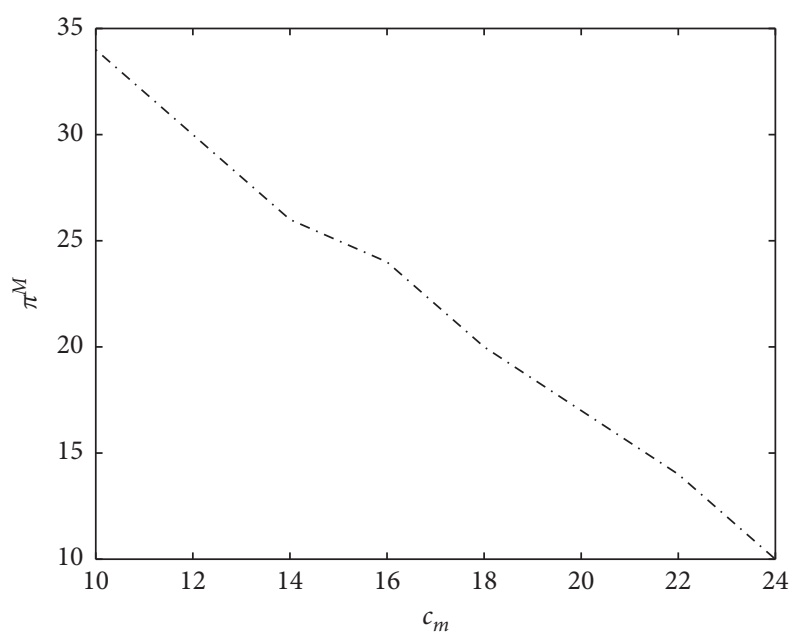

(a)

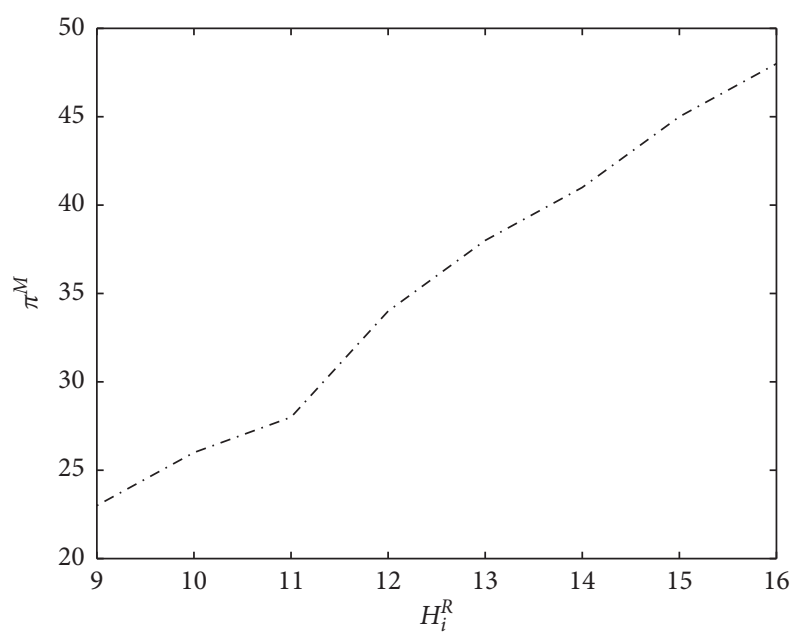

(b)

FIGURE 5: Impacts of unit operational cost on profit of the leader. (a) Impacts of manufacturing cost. (b) Impacts of holding cost.

manufacturer is increasing (see Figure 5(b)). The reason lies in the fact that higher unit holding cost may inhibit inappropriate ordering, which is helpful to make the profit rise up.

(3) From the slopes of the curves plotted in Figures 5(a) and 5(b), it can be seen that the manufacturer's profit is more sensitive to the unit manufacturing costs, compared with the unit holding cost.

6.3. Impacts of Critical Model Parameters on Retailers. As the follower of the VMI system, the retailer's maximal profit is also affected by the model parameters. In Figure 6(a), we present the relationship between the retailer's profit and the demand parameters $\left(\beta_{i}\right.$ and $\left.k_{i}\right)$ being associated with retailer $i$. Since there exists competition between the two retailers, in Figure 6(b), we also plot the relationship between the profits of the retailers and the retail price sensitivity coefficient of each retailer and its competitor's. In Figure 6(b), $\rho_{i}$ denotes the competitor's price sensitivity coefficient for retailer $i$.

From Figure 6, we have the following:

(1) For the retailer, higher sensitivity of advertising investment and prices results in greater profit (see Figure 6(a)).

(2) The slopes of the surface along the two axes in Figure 6(a)) also indicate that the retailer's profit is more sensitive to the advertising sensitivity coefficient $\left(k_{i}\right)$, compared with the price sensitivity coefficient $\left(\beta_{i}\right)$. In other words, for the retailer who wants to earn more profit, increasing the advertising investment may be a more efficient way than the pricing policy. These results support importance of jointly incorporating the advertising and pricing effects in the demand model proposed in this paper.

(3) For each retailer, its competitors' policy of retailing prices significantly affects the maximal profit of this retailer (see the slopes of the surface along the axis $\rho_{i}$ in Figure 6(b)). A little reduction of the competitor's unit retail price can lead to a sharp decrease of the concerned retailer's profit.

Since the retailer directly faces the market volatility in the VMI system, we finally investigate the impacts of the demand uncertainty on the retailer's maximal profit.

By choosing different standard deviations for the random demand, we solve Model (28) by Algorithm 1 so as to obtain different equilibrium solutions of the VMI system. Corresponding to the three standard deviations $\sigma=1,1.5$, and 2, the maximal profits of the retailer are presented in Figure 7, respectively.

Figure 7 indicates the following:

(1) Corresponding to the same standard deviation, the manufacturer's optimal advertising policy is less sensitive to the uncertainty of demand than that of the retailer.

(2) Greater deviation of demand generates more profit of the retailer (the follower of the VMI system). It says that, in the case of greater market volatility, the follower of the VMI system would like to report this situation to the leader (manufacturer). It also suggests that, for a practical VMI system, the established Stackelberg game model in this paper is helpful in light of efficient cooperation between the manufacturer and the retailers.

6.4. Impacts of Retailers' Competition. To explore the impact of competition on decision-making of VMI system, we take different coefficients of the cross price sensitivity, $\rho_{i j}$, so as to observe the change of the profits of the manufacturer and the retailers.

In Tables 2 and 3, we report the numerical results corresponding to two different cases: symmetric and asymmetric retailers.

The results in Tables 2 and 3 demonstrate the following: 


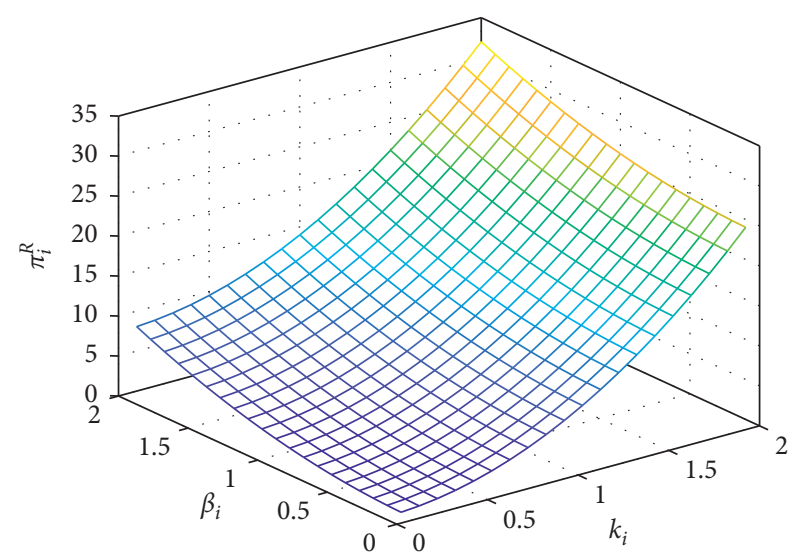

(a)

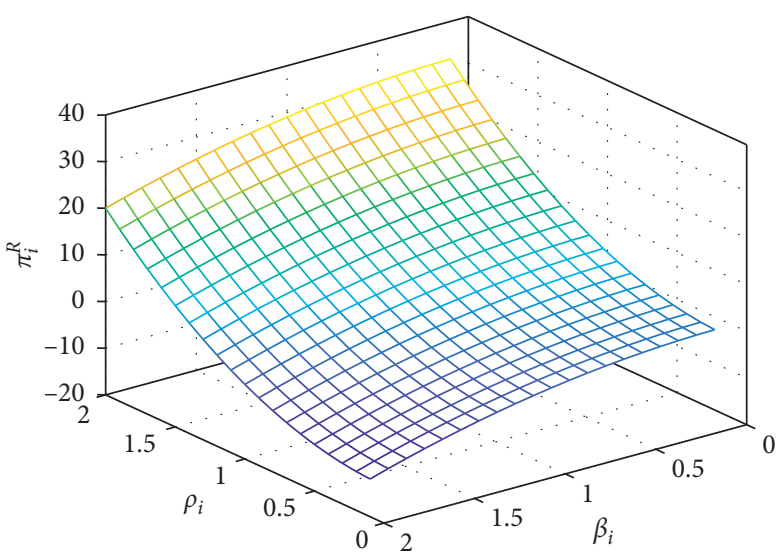

(b)

FIGURE 6: Impacts of demand parameters on the retailer's profit. (a) Impacts of own sensitivity parameters in demand. (b) Impacts of competition.

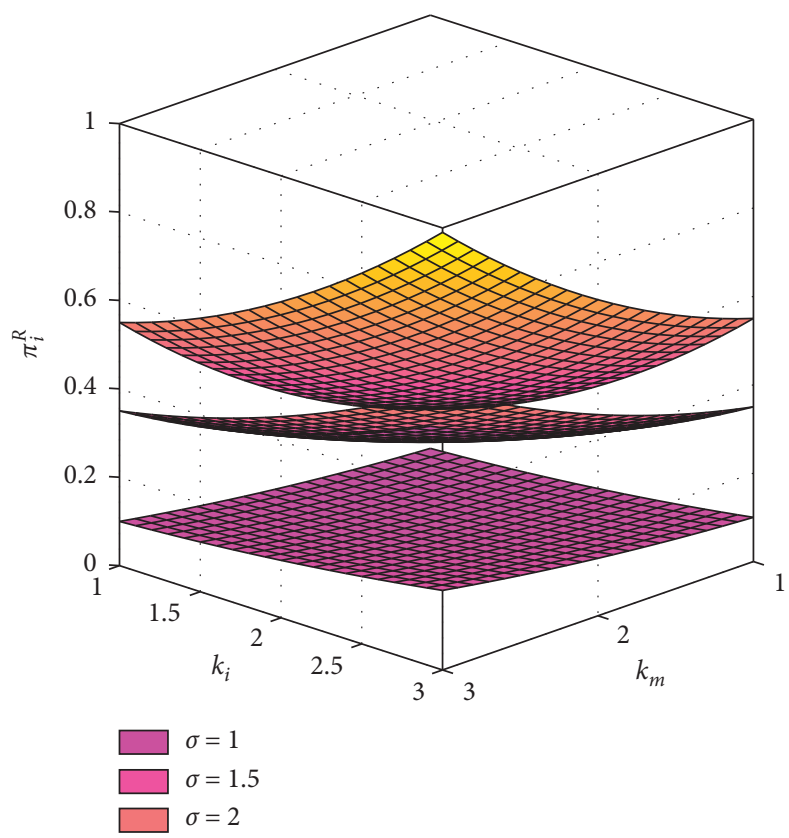

FIgURe 7: Effect of uncertainty on retailer's profit.

Table 2: Profits in symmetric case.

\begin{tabular}{lcccccccccc}
\hline$\rho_{i j}$ & 0 & 0.3 & 0.5 & 0.7 & 1 & 1.2 & 1.4 & 1.5 & 1.8 & 2.0 \\
\hline$\pi^{M}$ & 19.92 & 21.11 & 25.89 & 30.03 & 34.42 & 36.40 & 38.13 & 39.88 & 43.50 & 46.61 \\
\hline$\pi_{i}^{R}$ & 13.10 & 15.55 & 17.93 & 20.05 & 25.56 & 28.00 & 30.66 & 32.75 & 31.78 & 29.60 \\
\hline
\end{tabular}

Table 3: Profits in asymmetric case.

\begin{tabular}{lccccc}
\hline$\rho_{12}$ & $\rho_{21}$ & $d_{1}$ & $d_{2}$ & $\pi_{i}^{R}$ & $\pi_{2}^{R}$ \\
\hline 0.1 & 0.7 & 153 & 174 & 28.05 & 32.06 \\
0.3 & 1 & 233 & 191 & 24.46 & 29.60 \\
0.5 & 1.3 & 260 & 229 & 17.93 & 24.87 \\
0.7 & 1.6 & 285 & 251 & 14.13 & 20.05 \\
1 & 2 & 298 & 322 & 12.55 & 17.56 \\
\hline
\end{tabular}

(1) When the retailers are symmetric, the profits of the competitive manufacturer and the retailers are greater than those of the cooperative ones, respectively. In addition, with an increasing cross price sensitivity, $\rho_{i j}$, the manufacturer's profit goes up, while the retailers' profits initially increase and then decrease. The reason lies in the fact that the demands firstly increase and then decrease (see Figure 1(b)). In 
other words, the manufacturer should encourage the competition among the retailers by an effective approach.

(2) In the case of asymmetric retailers, the competition is more intense (corresponding to larger cross price sensitivity, $\rho_{i j}$ ), and the demands and the retailers' profits are less. Actually, as the competition between the retailers becomes fierce, the two competitive retailers have to reduce the retail prices in order to obtain greater market shares. However, the market demand generated by the reduction of prices may not sufficiently increase to balance the loss of profits caused by the lower retail prices.

\section{Conclusions and Directions of Future Research}

In this paper, we have constructed a stochastic bilevel programming model to formulate the VMI problems. The holding cost, shortage cost, competition of retailers, and randomness of demand have been taken into consideration such that optimal policies of distributed quantities, coop advertising expenditures, and pricing are obtained for the VMI problems.

For the established stochastic model, a deterministic equivalent formulation has been obtained by expectation method. Then, by reformulating the bilevel programming problem into an MPCC, we transform the MPCC into a series of standard constrained optimization subproblems in virtue of smoothing techniques such that an efficient algorithm is developed to solve the original model.

By sensitivity analysis, a number of practical managerial implications have been revealed in view of the model and algorithm:

(1) The participation rate depends on advertising expenditures from both the manufacturer and the retailer. There exists an optimal threshold of participation rate for the manufacturer, where the maximum profit of the manufacturer can be attained. Therefore, for the manufacturer, he/she should properly control his/her advertising expenditures to get the optimal participation rate. Furthermore, this optimal participation rate can be obtained by the proposed model and algorithm in this paper, which is specified by the intersection point of the manufacturer and retailer's cost-profit curves.

(2) The manufacturer's advertising policy is less sensitive to uncertainty of demand than the change of the retailer's advertising policy. The uncertainty of demand generates a great impact on the retailers' profit. The higher the degree of uncertainty, the greater the retailer's profit. Therefore, in the VMI system, the manufacturer should pay great attention to uncertainty of demand to avoid competitive inferior equilibrium in the VMI system.

(3) The manufacturer in the VMI system should concern about the differences caused by symmetric or asymmetric retailers. In the case of symmetric retailers, the profits of the competitive manufacturer and retailers are bigger than those of the cooperative ones. The manufacturer should encourage the competition between the retailers. In the case of asymmetric retailers, competition among the retailers leads to lower retail prices such that they can obtain greater market share, but the profit obtained from the increased market demand may be less than the loss caused by the lower retail prices. Therefore, the total profit of the VMI system may reduce.

In the future research, our model can be further extended to multiproduct and multimanufacturer VMI systems, instead of a single product and a single manufacturer. In addition, if the wholesale price is an endogenous decision variable and is a function with respect to the order quantities, it is valuable to develop new efficient algorithms to solve the constructed complicated model.

\section{Data Availability}

The data used to support the findings of this study are available from the corresponding author upon request.

\section{Conflicts of Interest}

The authors declare that there are no conflicts of interest about submission and publication of this paper.

\section{Authors' Contributions}

Zhong Wan conceived and designed the research plan and wrote the paper. Hua Deng, Yinxue Li, and Zhaoman Wan performed the mathematical modelling, development of the algorithm, and numerical analysis and wrote the paper.

\section{Acknowledgments}

This research was supported by the National Natural Science Foundation of China (Grant no. 71671190).

\section{References}

[1] A. Mateen, A. K. Chatterjee, and S. Mitra, "VMI for singlevendor multi-retailer supply chains under stochastic demand," Computers and Industrial Engineering, vol. 79, pp. 95-102, 2014.

[2] S. Bylka, "Non-cooperative strategies for production and shipment lot sizing in one vendor-multi-buyer system," International Journal of Production Economics, vol. 131, no. 1, pp. 372-382, 2011.

[3] G. P. Kiesmüller and R. A. C. M. Broekmeulen, "The benefit of VMI strategies in a stochastic multi-product serial two echelon system," Computers and Operations Research, vol. 37, no. 2, pp. 406-416, 2011.

[4] Y. Yu, G. Q. Huang, and L. Liang, "Stackelberg game-theoretic model for optimizing advertising, pricing and inventory policies in vendor managed inventory (VMI) production supply chains," Computers \& Industrial Engineering, vol. 57, no. 1, pp. 368-382, 2009. 
[5] Y. Li, Z. Wan, and J. Liu, "Bi-level programming approach to optimal strategy for vendor-managed inventory problems under random demand," The ANZIAM Journal, vol. 59, no. 2, pp. 247-270, 2017.

[6] A. A. Taleizadeh, S. T. A. Niaki, and F. Barzinpour, "Multiplebuyer multiple-vendor multi-product multi-constraint supply chain problem with stochastic demand and variable lead-time: a harmony search algorithm," Applied Mathematics and Computation, vol. 217, no. 22, pp. 9234-9253, 2011.

[7] Y. Su, J. Qin, P. Yang, and Q. Jiang, "A supply chain-logistics super-network equilibrium model for urban logistics facility network optimization," Mathematical Problems in Engineering, vol. 2019, Article ID 5375282, 12 pages, 2019.

[8] Z. H. Gümüs and C. A. Floudas, "Global optimization of nonlinear bilevel programming problems," Journal of Global Optimization, vol. 20, no. 1, pp. 1-31, 2001.

[9] S. Alaei, R. Alaei, and P. Salimi, "A game theoretical study of cooperative advertising in a single-manufacturer-two-retailers supply chain," International Journal of Advanced Manufacturing Technology, vol. 74, no. 1-4, pp. 101-111, 2014.

[10] S.-D. Wang, Y.-W. Zhou, J. Min, and Y.-G. Zhong, "Coordination of cooperative advertising models in a one-manufacturer two-retailer supply chain system," Computers and Industrial Engineering, vol. 61, no. 4, pp. 1053-1071, 2011.

[11] E. Almehdawe and B. Mantin, "Vendor managed inventory with a capacitated manufacturer and multiple retailers: retailer versus manufacturer leadership," International Journal of Production Economics, vol. 128, no. 1, pp. 292-302, 2010.

[12] M. M. SeyedEsfahani, M. Biazaran, and M. Gharakhani, "A game theoretic approach to coordinate pricing and vertical co-op advertising in manufacturer-retailer supply chains," European Journal of Operational Research, vol. 211, no. 2, pp. 263-273, 2011.

[13] J. Chaab and M. Rasti-Barzoki, "Cooperative advertising and pricing in a manufacturer-retailer supply chain with a general demand function: a game-theoretic approach," Computers and Industrial Engineering, vol. 99, pp. 112-123, 2016.

[14] P. D. Berger, "Vertical cooperative advertising ventures," Journal of Marketing Research, vol. 9, no. 3, pp. 309-312, 1972.

[15] P. D. Berger and T. Magliozzi, "Optimal Co-operative advertising decisions in direct-mail operations," The Journal of the Operational Research Society, vol. 43, no. 11, pp. 10791086, 1992.

[16] C. Fulop, "The role of advertising in the retail marketing mix," International Journal of Advertising, vol. 7, no. 2, pp. 99-117, 1988.

[17] M. Khouja and S. S. Robbins, "Linking advertising and quantity decisions in the single-period inventory model," International Journal of Production Economics, vol. 86, no. 2, pp. 93-105, 2003.

[18] J. D. Hettington and W. A. Dempsey, "Comparing the current effects and carryover of national-, regional-, and local-sponsor advertising," Journal of Advertising Research, vol. 45, no. 1, pp. 60-72, 2005.

[19] T. M. Somers, Y. P. Gupta, and S. R. Harriot, "Analysis of cooperative advertising expenditures: a transfer-function modeling approach," Journal of Advertising Research, vol. 30, no. 5, pp. 35-49, 2012.

[20] B. C. Giri and S. Sharma, "Manufacturer's pricing strategy in a two-level supply chain with competing retailers and advertising cost dependent demand," Economic Modelling, vol. 38, pp. 102-111, 2014.
[21] J. Xie and J. C. Wei, "Coordinating advertising and pricing in a manufacturer-retailer channel," European Journal of Operational Research, vol. 197, no. 2, pp. 785-791, 2009.

[22] A. Gerhard and B. Udo, "Vertical cooperative advertising and pricing decisions in a manufacturer-retailer supply chain: a game-theoretic approach," European Journal of Operational Research, vol. 223, no. 2, pp. 473-482, 2012.

[23] S. Karray and G. Zaccour, "Effectiveness of coop advertising programs in competitive distribution channels," International Game Theory Review, vol. 9, no. 2, pp. 151-167, 2007.

[24] P. De Giovanni, S. Karray, and G. Martín-Herrán, "Vendor management inventory with consignment contracts and the benefits of cooperative advertising," European Journal of Operational Research, vol. 272, no. 2, pp. 465-480, 2019.

[25] G. Aust and U. Buscher, "Game theoretic analysis of pricing and vertical cooperative advertising of a retailer-duopoly with a common manufacturer," Central European Journal of Operations Research, vol. 24, no. 1, pp. 127-147, 2016.

[26] J. A. Ahmadi and P. Hoseinpour, "A game-theoretic analysis for coordinating cooperative advertising in a supply chain," Journal of Optimization Theory and Applications, vol. 149, no. 1, pp. 138-150, 2011.

[27] G. Tian, M. C. Zhou, and P. Li, "Disassembly sequence planning considering fuzzy component quality and varying operational cost," IEEE Transactions on Automation Science and Engineering, vol. 15, no. 2, pp. 748-760, 2017.

[28] M. Xu, B. Zhou, and J. He, "Improving truncated Newton method for the logit-based stochastic user equilibrium problem," Mathematical Problems in Engineering, vol. 2019, Article ID 7313808, 15 pages, 2019.

[29] J.-Y. Lee and L. Ren, "Vendor-managed inventory in a global environment with exchange rate uncertainty," International Journal of Production Economics, vol. 130, no. 2, pp. 169-174, 2011.

[30] J. Ming, A. Rajapov, and S. Hayrutdinov, "Three-echelon supply chain contractual coordination with loss-averse multiple retailer preference," Mathematical Problems in Engineering, vol. 2019, Article ID 4927302, 11 pages, 2019.

[31] C. H. Huynh and W. Pan, "Operational strategies for supplier and retailer with risk preference under VMI contract," International Journal of Production Economics, vol. 169, pp. 413-421, 2015.

[32] K. Govindan, "The optimal replenishment policy for timevarying stochastic demand under vendor managed inventory," European Journal of Operational Research, vol. 242, no. 2, pp. 402-423, 2015.

[33] F. Huang, J. He, and J. Wang, "Coordination of VMI supply chain with a loss-averse manufacturer under quality-dependency and marketing-dependency," Journal of Industrial and Management Optimization, vol. 15, no. 4, pp. 1753-1772, 2019.

[34] A. Haji, M. Afzalabadi, and R. Haji, "Pricing and inventory decisions in a vendor managed inventory system with revenue sharing contract," Uncertain Supply Chain Management, vol. 6, no. 3, pp. 299-320, 2018.

[35] X. B. Zhang, S. Huang, and Z. Wan, "Optimal pricing and ordering in global supply chain management with constraints under random demand," Applied Mathematical Modelling, vol. 40, no. 23-24, pp. 10105-10130, 2016.

[36] X. Zhang, S. Huang, and Z. Wan, "Stochastic programming approach to global supply chain management under random additive demand," Operational Research, vol. 18, no. 2, pp. 389-420, 2018. 
[37] Q. Wei, J. Zhang, G. Zhu, R. Dai, and S. Zhang, "Retailer vs. vendor managed inventory with considering stochastic learning effect," Journal of the Operational Research Society, pp. 1-19, 2019.

[38] J. Zhao and Y. Zhou, "Bi-level programming model of cloud manufacturing services based on extension theory," Mathematical Problems in Engineering, vol. 2018, Article ID 9702910, 13 pages, 2018.

[39] Y.-C. Tsao, J.-C. Lu, N. An, F. Al-Khayyal, R. W. Lu, and G. Han, "Retailer shelf-space management with trade allowance: a Stackelberg game between retailer and manufacturers," International Journal of Production Economics, vol. 148, pp. 133-144, 2014.

[40] Y. Yuang, L. Liang, and G. Huang, "Leader-follower game in vendor-managed inventory system with limited production capacity considering wholesale and retail prices," International Journal of Logistics: Research and Applications, vol. 9, no. 4, pp. 335-350, 2006.

[41] Z. Wan, S. Zhang, and K. L. Teo, "Polymorphic uncertain nonlinear programming approach for maximizing the capacity of V-belt driving," Optimization and Engineering, vol. 15, no. 1, pp. 267-292, 2014.

[42] Z. Wan, H. Wu, and L. Dai, "A polymorphic uncertain equilibrium model and its deterministic equivalent formulation for decentralized supply chain management," Applied Mathematical Modelling, vol. 58, pp. 281-299, 2018.

[43] Z. Q. Luo, J. S. Pang, and D. Ralph, Mathematical Programs with Equilibrium Constraints, Cambridge University Press, Cambridge, UK, 1996.

[44] Y. Chen and Z. Wan, "A locally smoothing method for mathematical programs with complementarity constraints," ANZIAM Journal, vol. 55, no. 3, pp. 299-315, 2015.

[45] T. A. Burgin, "Inventory control with normal demand and Gamma lead times," Operational Research Quarterly (1970-1977), vol. 23, no. 1, pp. 73-80, 1972.

[46] S. Dempe and J. Dutta, "Is bilevel programming a special case of a mathematical program with complementarity constraints?" Mathematical Programming, vol. 131, no. 1-2, pp. 37-48, 2012.

[47] D. Aussel and A. Svensson, "Is pessimistic bilevel programming a special case of a mathematical program with complementarity constraints?" Journal of Optimization Theory and Applications, vol. 181, no. 2, pp. 504-520, 2019.

[48] D. M. Topkis and A. F. Veinott, Jr., "On the convergence of some feasible direction algorithms for nonlinear programming," SIAM Journal on Control, vol. 5, no. 2, pp. 268-279, 1967.

[49] J. R. Birge, L. Qi, and Z. Wei, “A variant of the Topkis-Veinott method for solving inequality constrained optimization problems," Applied Mathematics and Optimization, vol. 41, no. 3, pp. 309-330, 2000.

[50] X. Chen, Q. Du, X. Xiong et al., "Redefinition of cost-benefit efficiency of land-use projects: focusing on environmental cost," Mathematical Problems in Engineering, vol. 2019, Article ID 3126172, 14 pages, 2019. 